\title{
Location of Disease Onset
}

National Cancer Institute

\section{Source}

National Cancer Institute. Location of Disease Onset. NCI Thesaurus. Code C117884.

The anatomical location of the beginning or early stages of a disease. 